\title{
Simultaneous Measurements of Heat Capacity, Electrical Resistivity, and Hemispherical Total Emittance by a Pulse Heating Technique: Vanadium, 1500 to $2100 \mathrm{~K}^{*}$
}

\author{
A. Cezairliyan, F. Righini**, and J. L. McClure \\ Institute for Materials Research, National Bureau of Standards, Washington, D.C. 20234
}

(November 30, 1973)

\begin{abstract}
Simultaneous measurements of heat capacity, electrical resistivity, and hemispherical total emittance of vanadium in the temperature range 1500 to $2100 \mathrm{~K}$ by a subsecond duration, pulse heating technique are described. The results are expressed by the relations:

$$
\begin{aligned}
c_{p} & =56.34-3.839 \times 10^{-2} T+1.563 \times 10^{-5} T^{2} \\
\rho & =8.794+6.282 \times 10^{-2} T-6.804 \times 10^{-6} T^{2}
\end{aligned}
$$

where $c_{p}$ is in $\mathrm{J} \cdot \mathrm{mol}^{-1} \cdot \mathrm{K}^{-1}, \rho$ is in $10^{-8} \Omega \cdot \mathrm{m}$, and $T$ is in $\mathrm{K}$. The values for the hemispherical total emittance are: 0.313 at $1900 \mathrm{~K}$ and 0.332 at $2000 \mathrm{~K}$. Estimated inaccuracies of the measured properties are: 3 percent for heat capacity, 0.5 percent for electrical resistivity and 5 percent for hemispherical total emittance.
\end{abstract}

Key words: Electrical resistivity; emittance; heat capacity; high-speed measurements; high temperature; thermodynamics; thermophysics; vanadium.

\section{Introduction}

In this paper, application of a pulse heating technique to the simultaneous measurements of heat capacity, electrical resistivity, and hemispherical total emittance of vanadium in the temperature range 1500 to $2100 \mathrm{~K}$ is described.

The method is based on rapid resistive self-heating of the specimen from room temperature to high temperatures (above $1500 \mathrm{~K}$ ) in less than one second by the passage of an electrical current pulse through it; and on measuring, with millisecond resolution, such experimental quantities as current through the specimen, potential drop across the specimen, and specimen temperature. Details regarding the construction and operation of the measurement system, the methods of measuring experimental quantities, and other pertin- ent information, such as the formulation of relations for properties, error analysis, etc. are given in earlier publications $[1,2]^{1}$.

In the following sections of this paper a new approach-tabular format-is adopted in presenting information on the specimen, measurements, system characteristics, results, and errors.

The reasons for adopting this format are: (1) to facilitate the preparation of manuscripts, (2) to standardize the contents of the papers on measurements using the present or similar systems in other laboratories, (3) to facilitate information retrieval by the reader, (4) to provide a means for efficient and accurate identification, coding, characterization, and data reduction by scientific and technical information centers, and (5) to ultimately lead to the computerized preparation of papers.

\footnotetext{
* This work was supported in part by the U.S. Air Force Office of Scientific Research. ** Guest scientist from the Istituto di Metrologia "G. Colonnetti" in Torino, under a fellowship from the Consiglio Nazionale delle Ricerche of Italy.
}

${ }^{1}$ Figures in brackets indicate the literature references at the end of this paper. 


\section{Measurements}

The details regarding the vanadium specimen used in the present measurements are given in table 1 . A summary of the measurement technique and the operational characteristics of the system is given in table 2. The polynomial functions (obtained by the least squares method) that represent the experimental results are given in table 3 . The final values on properties at 100 degree temperature intervals computed using the functions are given in table 4 . The experimental results are presented in the appendix. Each number tabulated in the appendix represents results from over 50 original data points. An estimate of errors in the measured and computed quantities is given in table 5. All values reported in this paper are based on the International Practical Temperature Scale of 1968 [3]. In all computations, the geometrical quantities are based on their room temperature (298 K) dimensions.

TABLE 1. Specimen information

\begin{tabular}{|c|c|c|c|}
\hline No. & Item & Unit & Explanation \\
\hline 1 & Substance & & Vanadium (polycrystalline) \\
\hline 2 & Source* & & $\begin{array}{l}\text { Materials Research } \\
\text { Corporation }\end{array}$ \\
\hline 3 & Purity & & $99.9+\%$ \\
\hline 4 & Impurities & & Listed in table la \\
\hline 5 & Geometry & & $\begin{array}{l}\text { Tube made from rod by } \\
\text { electro-erosion }\end{array}$ \\
\hline \multirow[t]{6}{*}{6} & Dimensions & & \\
\hline & total length & $\mathrm{mm}$ & 76.26 \\
\hline & effective $^{* *}$ length & $\mathrm{mm}$ & 25.53 \\
\hline & outside diameter & $\mathrm{mm}$ & 6.3 \\
\hline & wall thickness & $\mathrm{mm}$ & 0.5 \\
\hline & blackbody hole & $\mathrm{mm}$ & $0.5 \times 1$ (rectangular) \\
\hline \multirow[t]{3}{*}{7} & Weight & & \\
\hline & total weight & g & 4.319 \\
\hline & effective ${ }^{* *}$ weight & $\mathrm{g}$ & 1.438 \\
\hline \multirow[t]{4}{*}{8} & Characteristics & & \\
\hline & atomic weight & & 50.942 \\
\hline & density & $\mathrm{g} \cdot \mathrm{cm}^{-3}$ & 6.1 \\
\hline & resistivity at $293 \mathrm{~K}$ & $10^{-8} \Omega \cdot \mathrm{m}$ & 21.7 \\
\hline 9 & Special treatment & & $\begin{array}{l}\text { Heat treated by pulse } \\
\text { heating before the experi- } \\
\text { ments }(30 \text { pulses to } \\
1900 \mathrm{~K})\end{array}$ \\
\hline
\end{tabular}

*The supplier is identified in this paper in order to adequately characterize the specimen. Such an identification does not imply recommendation or endorsement by the National Bureau of Standards.

**Effective refers to the portion of the specimen between the voltage probes.
TABLE la. Impurities in the specimen*

(according to the manufacturer's analysis)

\begin{tabular}{l|c|c|c|c|c|c}
\hline \hline Element & $\mathrm{C}$ & $\mathrm{Fe}$ & $\mathrm{Nb}$ & $\mathrm{N}$ & $\mathrm{O}$ & $\mathrm{P}$ \\
ppm & 120 & 20 & 60 & 10 & 15 & 15 \\
\hline Element & $\mathrm{Si}$ & $\mathrm{Ta}$ & $\mathrm{Ti}$ & $\mathrm{W}$ & $\mathrm{Zr}$ & \\
ppm & 50 & 70 & 10 & 30 & 15 & \\
\hline
\end{tabular}

*The total amount of all other detected elements is less than $50 \mathrm{ppm}$, each element being below $10 \mathrm{ppm}$ limit.

TABLE 2. Measurement technique and system characteristics

\begin{tabular}{|c|c|c|c|}
\hline No. & Item & Unit & Explanation and Data \\
\hline 1 & General technique & & $\begin{array}{l}\text { Pulse heating } \\
\text { (subsecond) }\end{array}$ \\
\hline 2 & Voltage measurement & & $\begin{array}{l}\text { Across tungsten knife- } \\
\text { edge probes }\end{array}$ \\
\hline 3 & Current measurement & & $\begin{array}{l}\text { Across standard re- } \\
\text { sistor }(0.001 \Omega) \text { in } \\
\text { series with the } \\
\text { specimen }\end{array}$ \\
\hline 4 & Temperature measurement & & $\begin{array}{l}\text { High-speed photo- } \\
\text { electric pyrometer } \\
{[4]}\end{array}$ \\
\hline 5 & Specimen environment & & $\begin{array}{l}\text { Vacuum } \sim 1.3 \times 10^{-3} \\
\mathrm{~N} \cdot \mathrm{m}^{-2}\left(\sim 10^{-5}\right. \\
\text { torr })\end{array}$ \\
\hline 6 & Power source & & $\begin{array}{l}\text { Battery bank ( } 14 \text { series- } \\
\text { connected } 2 \mathrm{~V} \\
\text { batteries, capacity } \\
1100 \mathrm{~A} \cdot \mathrm{h} \text { each) }\end{array}$ \\
\hline 7 & Recording & & $\begin{array}{l}\text { Digital data acquisition } \\
\text { system }\end{array}$ \\
\hline 8 & Signal resolution & & $\sim 0.01 \%$ (at full scale) \\
\hline 9 & Time resolution & ms & 0.4 \\
\hline 10 & Data processing & & Time-sharing computer \\
\hline 11 & Date of measurements & & August 1973 \\
\hline 12 & Number of experiments & & 4 \\
\hline 13 & Temperature range & $\mathrm{K}$ & $1500-2100$ \\
\hline 14 & Temperature subranges & $\mathrm{K}$ & $\begin{array}{l}\text { I }(1480-1710) \\
\text { II }(1690-1890) \\
\text { III }(1810-2050) \\
\text { IV }(2000-2130)\end{array}$ \\
\hline 15 & Experiment duration & $\mathrm{ms}$ & $600-620$ \\
\hline 16 & Current pulse length & $\mathrm{ms}$ & $400-420$ \\
\hline 17 & Imparted power & W & $4000-5200$ \\
\hline 18 & Current & A & $1300-1600$ \\
\hline 19 & Rate of current change & $\mathrm{A} \cdot \mathrm{ms}^{-1}$ & $0.3-0.6$ \\
\hline 20 & Heating rate & $\mathrm{K} \cdot \mathrm{ms}^{-1}$ & $3.9-4.5$ \\
\hline 21 & Cooling rate & $\mathrm{K} \cdot \mathrm{ms}^{-1}$ & $0.04-0.15$ \\
\hline 22 & $\begin{array}{l}\text { Radiative heat loss } \\
\text { (\% of input power) }\end{array}$ & & $\begin{array}{l}1 \% \text { at } 1500 \mathrm{~K} \\
4 \% \text { at } 2100 \mathrm{~K}\end{array}$ \\
\hline
\end{tabular}


TABLE 3. Functional representation of results on vanadium

\begin{tabular}{c|c|c}
\hline \hline $\begin{array}{c}\text { Heat capacity } \\
\left(\mathrm{J} \cdot \mathrm{mol}^{-1} \cdot \mathrm{K}^{-1}\right)\end{array}$ & $\begin{array}{c}\text { Resistivity } \\
\left(10^{-8} \Omega \cdot \mathrm{m}\right)\end{array}$ & $\begin{array}{c}\text { Hemispherical } \\
\text { total emittance }\end{array}$ \\
\hline$c_{p}=A+B T+C T^{2}$ & $\rho=A+B T+C T^{2}$ & $\epsilon=A+B T$ \\
$A=56.34$ & $A=8.794$ & $A=-5.413 \times 10^{-2}$ \\
$B=-3.839 \times 10^{-2}$ & $B=6.282 \times 10^{-2}$ & $B=1.930 \times 10^{-4}$ \\
$C=1.563 \times 10^{-5}$ & $C=-6.804 \times 10^{-6}$ & \\
$1500 \mathrm{~K}<T<2100 \mathrm{~K}$ & $1500 \mathrm{~K}<T<2100 \mathrm{~K}$ & $1880 \mathrm{~K}<T<2050 \mathrm{~K}$ \\
$\sigma^{*}=1.1 \%$ & $\sigma^{*}=0.06 \%$ & $\sigma^{*}=0.05 \%$ \\
\hline
\end{tabular}

*Standard deviation.

TABLE 4. Results on properties of vanadium

\begin{tabular}{|c|c|c|c|}
\hline $\begin{array}{c}T \\
(\mathrm{~K})\end{array}$ & $\begin{array}{c}c_{p} \\
\left(\mathrm{~J} \cdot \mathrm{mol}^{-1} \cdot \mathrm{K}^{-1}\right)\end{array}$ & $\begin{array}{c}\rho \\
\left(10^{-8} \Omega \cdot \mathrm{m}\right)\end{array}$ & $\epsilon$ \\
\hline 1500 & 33.92 & 87.72 & --- \\
\hline 1600 & 34.93 & 91.89 & --- \\
\hline 1700 & 36.25 & 95.92 & --- \\
\hline 1800 & 37.88 & 99.83 & --- \\
\hline 1900 & 39.82 & 103.59 & 0.313 \\
\hline 2000 & 42.08 & 107.22 & 0.332 \\
\hline 2100 & 44.65 & 110.71 & --- \\
\hline
\end{tabular}

TABLE 5. Error analysis (at $2000 \mathrm{~K}$ )

\begin{tabular}{|c|c|c|}
\hline Quantity & Imprecision* & Inaccuracy** \\
\hline Temperature..... & $0.5 \mathrm{~K}$ & $4 \mathrm{~K}$ \\
\hline Voltage................. & $0.03 \%$ & $0.1 \%$ \\
\hline Current.................. & $0.03 \%$ & $0.1 \%$ \\
\hline Heat capacity..................... & $1 \%$ & $3 \%$ \\
\hline Electrical resistivity ................ & $0.1 \%$ & $0.5 \%$ \\
\hline Hemispherical total emittance..... & $0.1 \%$ & $5 \%$ \\
\hline
\end{tabular}

*Imprecision refers to the standard deviation of an individual point as computed from the difference between measured value and that from the smooth function obtained by the least squares method.

**Inaccuracy refers to the estimated total error (random and systematic).

\section{Discussion}

The heat capacity, electrical resistivity, and hemispherical total emittance of vanadium measured in this work are presented and compared graphically with those reported in the literature in figures 1,2 and 3 , respectively.

The heat capacity results of this work are approximately 6-8 percent lower than those of Jaeger and Veenstra [5] and Fieldhouse and Land [6], and are approximately 8 percent higher than those of Peletskii et al. [7] over the respective overlapping regions. The results reported in the literature were for temperatures below $1900 \mathrm{~K}$. In this work, the measurements are

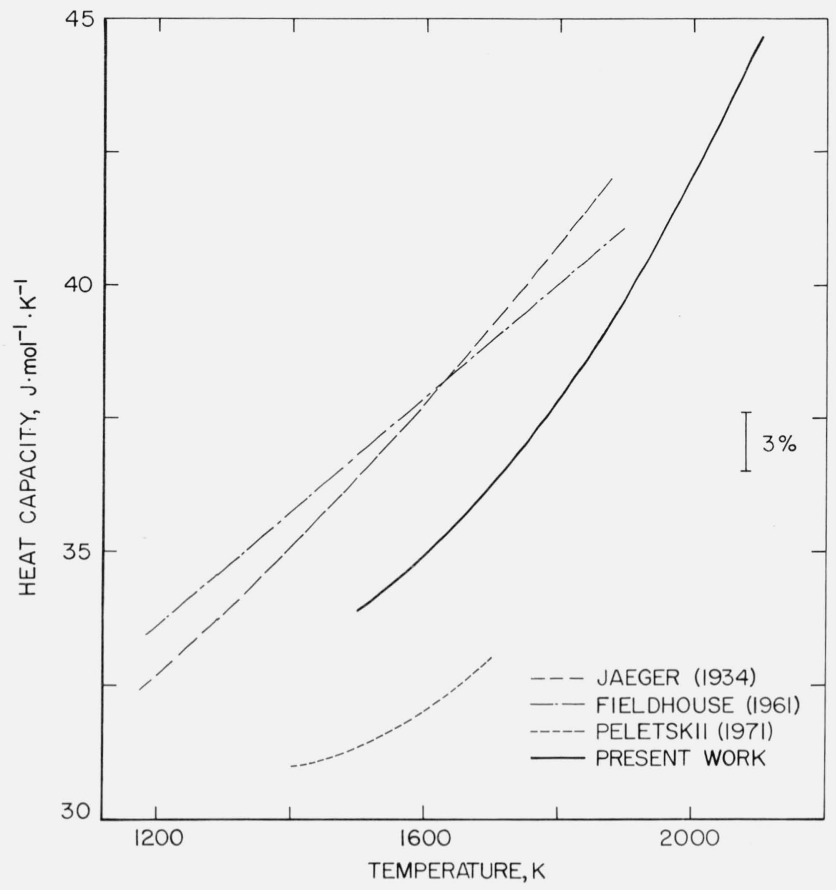

Figure 1. Heat capacity of vanadium reported in the literature.

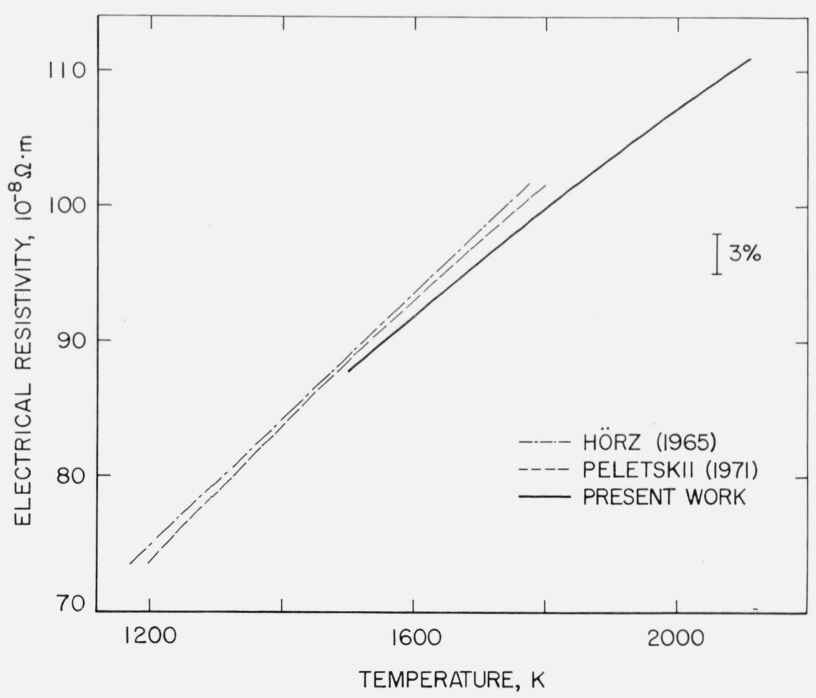

FiguRE 2. Electrical resistivity of vanadium reported in the literature.

extended to $2100 \mathrm{~K}$, which is approximately $90 \mathrm{~K}$ below the melting point of vanadium.

The electrical resistivity results are in reasonably good agreement (maximum differences about 2\%) with those reported by Hörz et al. [8] and Peletskii et al. [7]. At $293 \mathrm{~K}$, the observed electrical resistivity is approximately 3 percent higher than the value $\left(21.02 \times 10^{-8} \Omega \cdot \mathrm{m}\right)$ reported by Peletskii et al. [7]. In the range of the present measurements, vanadium showed a negative departure from linearity in the 


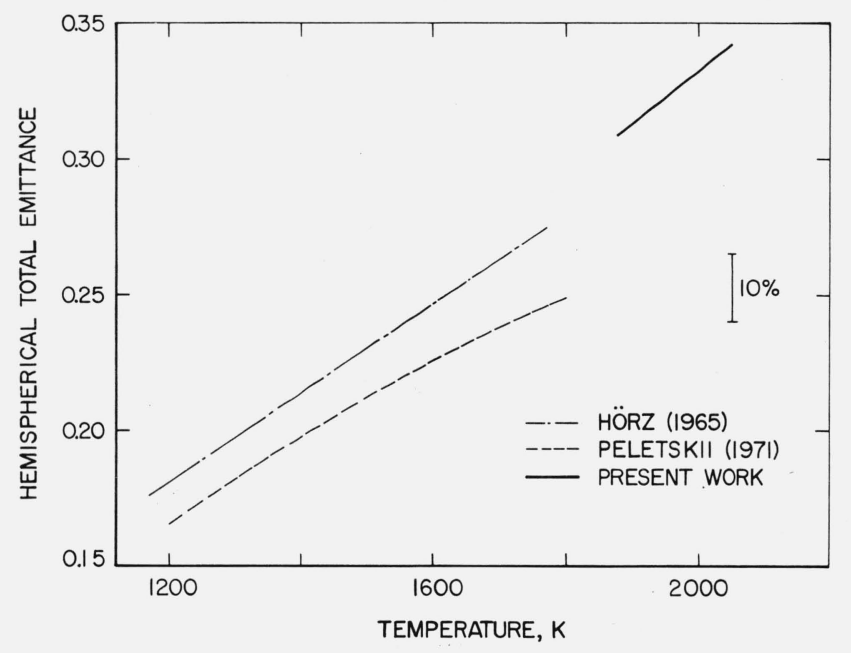

FIGURE 3. Hemispherical total emittance of vanadium reported in the literature.

temperature dependence of electrical resistivity. A similar behavior was previously noted for niobium [9] and tantalum [10], which belong to the same group (V) on the periodic table.

Considerable differences in hemispherical total emittance results of various investigators may be expected due to the differences in specimen surface conditions. The difference of the present results from the extrapolated values of Hörz et al. [8] is approximately 6 percent.

Similar to the earlier results on other refractory metals $[2,9,10,11]$ obtained with the present measurement system, heat capacity of vanadium at high temperatures is considerably higher than the Dulong and Petit value of $3 R$. Some of this departure is due to $c_{p}-c_{v}$ and the electronic terms. However, they do not account for the entire difference. Heat capacity above the Debye temperature may be expressed by

$$
c_{p}=A-\frac{B}{T^{2}}+C T+\Delta c
$$

where the constant term is $3 R\left(24.943 \mathrm{~J} \cdot \mathrm{mol}^{-1} \cdot \mathrm{K}^{-1}\right)$, the term in $T^{-2}$ is the first term in the expansion of the Debye function, the term in $T$ represents $c_{p}-c_{v}$ and electronic contributions, and the quantity $\Delta c$ represents excess in measured heat capacity at high temperatures, which is not accounted for by the first three terms. The coefficients $B\left(1.50 \times 10^{5}\right)$ and $C\left(4.86 \times 10^{-3}\right)$ were obtained from heat capacity values at $270 \mathrm{~K}[12,13]$ and at $1000 \mathrm{~K}$. The value at $1000 \mathrm{~K}$ was estimated based on the extrapolation of the present work results and the low temperature results reported in the literature $[12,13]$.

Using the above equation and the heat capacity results of this work, the quantity $\Delta c$ was computed for temperatures above $1500 \mathrm{~K}$. The results for $\Delta c$ in $\mathrm{J} \cdot \mathrm{mol}^{-1} \cdot \mathrm{K}^{-1}$ are: 1.8 at $1500 \mathrm{~K}, 4.2$ at $1800 \mathrm{~K}$, and 9.5 at $2100 \mathrm{~K}$.

Although the mechanisms of vacancy generation become important at high temperatures, it was not possible to attribute the high heat capacity values entirely to vacancies. To demonstrate this, a crude estimate of the contribution of vacancies to heat capacity was made using the method described in a previous publication [2]. The results indicate that vacancy contribution would be small, approximately $0.03 \mathrm{~J} \cdot \mathrm{mol}^{-1} \cdot \mathrm{K}^{-1}$ at $1500 \mathrm{~K}$ and $0.5 \mathrm{~J} \cdot \mathrm{mol}^{-1} \cdot \mathrm{K}^{-1}$ at $2100 \mathrm{~K}$, and would not account for the high heat capacity values. If the entire difference between measured and computed (using the first three terms in the above equation) heat capacities is attributed to vacancies, values of $1.1 \mathrm{eV}$ for vacancy formation energy and 3.8 percent for vacancy concentration at the melting point are obtained. Both of these values, especially the concentration, seem to be unrealistic for vanadium.

The new format adopted in this paper has demonstrated the feasibility of concise yet complete and systematic documentation of measurements performed with the present system. For reasons enumerated in the Introduction, it is hoped that the approach of a standardized quasi-tabular presentation will find wide acceptance among the experimenters in the same and related fields.

The authors express their gratitude to C. W. Beckett for his encouragement of research in high-speed thermophysical measurements and to M. S. Morse for his help with the electronic instrumentation. 


\section{Appendix}

TABLE A-1. Experimental results on heat capacity and electrical resistivity of vanadium

\begin{tabular}{|c|c|c|c|c|}
\hline \hline $\begin{array}{c}\text { Temperature } \\
(\mathrm{K})\end{array}$ & $\begin{array}{c}c_{p} \\
\left(\mathrm{~J} \cdot \mathrm{mol}^{-1} \cdot \mathrm{K}^{-1}\right)\end{array}$ & $\begin{array}{c}\Delta c_{p}{ }^{*} \\
(\%)\end{array}$ & $\begin{array}{c}\rho \\
\left(10^{-8} \Omega \cdot \mathrm{m}\right)\end{array}$ & $\begin{array}{r}\Delta \rho^{*} \\
(\%)\end{array}$ \\
\hline 1500 & 33.48 & -1.32 & 87.66 & -0.06 \\
1550 & 34.50 & +0.33 & 89.81 & -0.01 \\
1600 & 35.32 & +1.10 & 91.93 & +0.05 \\
1650 & 35.88 & +0.92 & 94.03 & +0.12 \\
1700 & 35.81 & -1.23 & 95.83 & -0.09 \\
1750 & 37.20 & +0.46 & 97.86 & -0.03 \\
1800 & 38.26 & +0.99 & 99.87 & +0.05 \\
1850 & 38.61 & -0.53 & 101.69 & -0.03 \\
1900 & 39.71 & -0.30 & 103.56 & -0.02 \\
1950 & 40.80 & -0.29 & 105.40 & -0.02 \\
2000 & 41.96 & -0.30 & $107.20 \cdot$ & -0.01 \\
2050 & 42.72 & -1.43 & 109.01 & +0.03 \\
2100 & 45.34 & +1.51 & 110.70 & 0.00 \\
\hline
\end{tabular}

${ }^{*}$ The quantities $\Delta c_{p}$ and $\Delta \rho$ are percentage deviations of the individual results from the smooth functions represented by the pertinent equations in table 3 .

TABLE A-2. Experimental results on hemispherical total emittance of vanadium

\begin{tabular}{|c|c|c|c|c|c|}
\hline \hline $\begin{array}{c}\text { Temperature } \\
(\mathrm{K})\end{array}$ & $\epsilon$ & $\begin{array}{c}\Delta \epsilon^{*} \\
(\%)\end{array}$ & $\begin{array}{c}\text { Temperature } \\
(\mathrm{K})\end{array}$ & $\epsilon$ & $\begin{array}{c}\Delta \epsilon^{*} \\
(\%)\end{array}$ \\
\hline 1874.5 & 0.307 & -0.12 & 2022.6 & 0.336 & -0.06 \\
1878.4 & 0.308 & -0.03 & 2028.0 & 0.337 & -0.02 \\
1882.4 & 0.309 & +0.03 & 2033.4 & 0.338 & +0.01 \\
1886.4 & 0.310 & +0.06 & 2038.9 & 0.339 & +0.02 \\
1890.5 & 0.311 & +0.06 & 2044.5 & 0.341 & +0.02 \\
1894.7 & 0.312 & +0.03 & 2050.1 & 0.342 & +0.01 \\
\hline
\end{tabular}

${ }^{*}$ The quantity $\Delta \epsilon$ is percentage deviation of the individual results from the smooth function represented by the pertinent equation in table 3 .

\section{References}

[1] Cezairliyan, A., Design and operational characteristics of a high-speed (millisecond) system for the measurement of thermophysical properties at high temperatures. J. Res. Nat. Bur. Stand. (U.S.) 75C (Eng. and Instr.), No. 1, 7-18 (Jan.Mar. 1971).

[2] Cezairliyan, A., Morse, M. S., Berman, H. A., and Beckett, C. W., High-speed (subsecond) measurement of heat capacity, electrical resistivity, and thermal radiation properties of molybdenum in the range 1900 to $2800 \mathrm{~K}$. J. Res. Nat. Bur. Stand. (U.S.) 74A (Phys. and Chem.), No. 1, 65-92 (Jan.Feb. 1970).

[3] International Practical Temperature Scale of 1968. Metrologia 5, 35 (1969).

[4] Foley, G. M., High-speed optical pyrometer, Rev. Sci. Instr. 41, 827 (1970).

[5] Jaeger, F. M., and Veenstra, W. A., The exact measurement of the specific heats of solid substances at high temperatures. VI. The specific heats of vanadium, niobium, tantalum and molybdenum. Rec. Trav. Chim. 53, 677 (1934).

[6] Fieldhouse, I. B., and Lang, J. I., Measurement of thermal properties. Report WADD TR 60-904 (1961).

[7] Peletskii, V. E., Druzhinin, V. P., and Sobel', Ya. G., Thermophysical properties of vanadium at high temperatures. High Temp.-High Press. 3, 153 (1971).

[8] Hörz, G., Gebhardt, E., and Dürrschnabel. W., Emission- vermögen und elektrischer widerstand von vanadium, vanadium-stickstoff- und vanadium-sauerstoff-mischkristallen. Z. Metallkunde 56, 554 (1965).

[9] Cezairliyan, A., High-speed (subsecond) measurement of heat capacity, electrical resistivity, and thermal radiation properties of niobium in the range 1500 to 2700 K. J. Res. Nat. Bur. Stand. (U.S.) 75A (Phys. and Chem.), No. 6, 565-571 (Nov.Dec. 1971).

[10] Cezairliyan, A., McClure, J. L., and Beckett, C. W., High-speed (subsecond) measurement of heat capacity, electrical resistivity, and thermal radiation properties of tantalum in the range 1900 to $3200 \mathrm{~K}$, J. Res. Nat. Bur. Stand (U.S.) 75A (phys. and Chem.), No. 1, 1-13 (Jan.-Feb. 1971).

[11] Cezairliyan, A., and McClure, J. L., "High-speed (subsecond) measurement of heat capacity, electrical resistivity, and thermal radiation properties of tungsten in the range 2000 to 3600 K", J. Res. Nat. Bur. Stand. (U.S.) 75A (Phys. and Chem.), No. 4, 283-290 (July-Aug. 1971).

[12] Bieganski, Z., and Stalinski, B., Heat capacities and thermodynamic functions of vanadium and vanadium hydride within the range 24 to $340 \mathrm{~K}$. The hydrogen contribution to the heat capacity of transition metal hydrides. Bull. Acad. Polon. Sci. Ser. Sci. Chim. 9, 367 (1961).

[13] Anderson, C. T., The heat capacities of vanadium, vanadium trioxide, vanadium tetroxide and vanadium pentoxide at low temperatures. J. Am. Chem. Soc. 58, 564 (1936).

(Paper 78A2-807) 